\title{
Colletotrichum gloeosporioides sensu stricto Is a Pathogen of Leaf Anthracnose on Evergreen Spindle Tree (Euonymus japonicus)
}

Lin Huang, Qiu-Cheng Li, and Ya Zhang, College of Forestry and Co-Innovation Center for Sustainable Forestry in Southern China, Nanjing Forestry University, Nanjing, Jiangsu 210037, China; De-Wei Li, The Connecticut Agricultural Experiment Station Valley Laboratory, Windsor 06095; and Jian-Ren Ye, College of Forestry and Co-Innovation Center for Sustainable Forestry in Southern China, Nanjing Forestry University, Nanjing, Jiangsu 210037, China

\begin{abstract}
Huang, L., Li, Q.-C., Zhang, Y., Li, D.-W., and Ye, J.-R. 2016. Colletotrichum gloeosporioides sensu stricto is a pathogen of leaf anthracnose on evergreen spindle tree (Euonymus japonicus). Plant Dis. 100:672-678.

The genus Colletotrichum is considered the eighth most important group of plant-pathogenic fungi in the world due to its scientific and economic importance. Colletotrichum spp. cause anthracnose disease in a wide range of economically important plants. Euonymus japonicus Thunb. (Celastraceae) is a broad-leaved evergreen tree that is widely planted in the parks and landscapes of China. An anthracnose occurs on

E. japonicus in China but there has been a disagreement on the identity of the fungal pathogen. In this study, the fungal isolate HYCG2-3 was determined by Koch's postulates to be a pathogen on E. japonicus. Based on the morphological and molecular methods, isolate HYCG2-3 was identified as Colletotrichum gloeosporioides sensu stricto within the C. gloeosporioides species complex.
\end{abstract}

The genus Colletotrichum Corda 1831 has a broad host range that includes over 3,200 species of mono- and dicotyledonous plants (Crous et al. 2004; Dean et al. 2012; O'Connell et al. 2012). Members of this genus cause major losses to economically important crops, especially fruit, vegetables, and ornamentals (Crouch et al. 2009; Kamle et al. 2013; Prusky 1996; Su et al. 2011). Its distribution is primarily in tropical and subtropical areas; however, a number of prominent species infect temperate crops (Cannon et al. 2012). These pathogens use a multistage hemibiotrophic infection strategy, which had emerged as a tractable model for studying fungal pathogenicity and plant immune responses (Huser et al. 2009; Narusaka et al. 2009; O'Connell et al. 2004; Perfect et al. 1999). The genus Colletotrichum is currently considered the eighth most important group of plant-pathogenic fungi in the world due to its scientific and economic importance (Dean et al. 2012).

Colletotrichum, an asexual genus, is linked to its sexual state, genus Glomerella Spauld. \& H. Schrenk 1903 (Kirk et al. 2008; Ocfemia and Agati 1925; Shear and Wood 1907; Sutton 1980). According to the $1 \mathrm{~F}=1 \mathrm{~N}$ principle (namely, one fungus has only one name) adopted by the International Code of Nomenclature for algae, fungi, and plants (McNeill et al. 2012), Colletotrichum has priority over Glomerella and was chosen as the current name (Kirk et al. 2013). In spite of significant developments in fungal systematics in the last two decades, the taxonomy of genus Colletotrichum is far from fully solved (Dean et al. 2012). Uncertainties still exist over the systematics of the pathogens in this genus. The number of accepted species ranges from 11 in von Arx (1957), 22 in Sutton (1980), about 40 in Sutton (1992), and 60 in the Dictionary of the Fungi (Kirk et al. 2008). There are also 809 records in Index Fungorum and 883 epithets in MycoBank (Index Fungorum 2015; MycoBank 2015). The true number of accepted species still remains unknown. One of the most confusing species is Colletotrichum gloeosporioides (Penz.) Penz. \& Sacc. For example,

Corresponding author: J.-R. Ye; E-mail: jrye@njfu.edu.cn

Accepted for publication 8 September 2015.

http://dx.doi.org/10.1094/PDIS-07-15-0740-RE

(C) 2016 The American Phytopathological Society
594 species of Colletotrichum were demoted by von Arx (1957) to synonyms of $C$. gloeosporioides sensu lato (s.l.), while Kirk et al. (2008) considered this species complex to have 600 synonyms. Based on morphological studies and phylogenetic analyses using actin (ACT), calmodulin (CAL), chitin synthase 1 (CHS-1), glyceraldehyde-3-phosphate dehydrogenase (GAPDH), and internal transcribed spacers (ITS), Weir et al. (2012) segregated the $C$. gloeosporioides species complex into 22 species and one subspecies.

Euonymus japonicus Thunb. (Celastraceae) is a broad-leaved evergreen tree widely planted as an ornamental in the parks and landscapes of China. Its red clusters of fruit among the green foliage are of high visual value in the fall. However, Euonymus spp. are often seriously damaged by insects and microorganisms (Yi et al. 2003). Anthracnose is one of the diseases caused by a fungus infecting the euonymus shrub. At present, there is a disagreement on the identity of the pathogen of this disease. Lee et al. (2005) considered that C. boninense was the pathogen of anthracnose. However, Wang et al. (1986) and Shang and Qiu (1992) attributed C. gloeosporioides in the anthracnose on E. japonicus. Because C. gloeosporioides is a species complex, the identity of the pathogen remains undetermined.

The objectives of this study were to (i) characterize the pathogen of anthracnose on evergreen spindle trees in Nanjing, China and (ii) determine the identity of the pathogen with both morphological and multilocus phylogenetic methods.

\section{Materials and Methods}

Colletotrichum isolation. To isolate the fungus, infected leaves of E. japonicas with symptoms of anthracnose were randomly collected with a pair of sterile scissors from the campus of Nanjing Forestry University and the Xuan Wu Lake park in Nanjing, China in September 2014. These infected leaves were surface disinfested by immersion in $100 \%$ ethanol for $30 \mathrm{~s}$ and dried in sterilized petri dishes. Margins of the lesions were cut into small pieces ( 2 to 3 by 2 to $3 \mathrm{~mm}$ ), placed on $2 \%$ potato dextrose agar (PDA) (five pieces per plate), and incubated at $28^{\circ} \mathrm{C}$ for 7 days in the dark.

Conidial masses were picked from sporulating colonies with a needle and pure cultures were obtained by monosporic isolation using the technique of serial dilutions ( $\mathrm{Li}$ et al. 2007). Monosporic cultures 
were transferred to new PDA plates and grown for further morphological and cultural characterization.

Pathogenicity tests. Ten purified fungal isolates were obtained as described above. Because these isolates shared almost identical morphological characteristics, strain HYCG2-3 was randomly selected for the pathogenicity assay and morphological description.

For Koch's postulates, HYCG2-3 was used to inoculate healthy leaves of E. japonicus. Fresh leaves of E. japonicus (15 days old) were used for pathogenicity testing. Conidia of HYCG2-3 were collected from 10-day-old cultures on PDA and suspended in sterile distilled water. The conidial suspensions were adjusted to concentrations of $10^{5}, 10^{6}$, and $10^{7}$ conidia $\mathrm{ml}^{-1}$. The leaves were wounded with a redhot needle $1 \mathrm{~mm}$ in diameter. Ten wounded leaves were inoculated with each spore concentration $\left(10^{5}, 10^{6}\right.$, or $10^{7}$ conidia $\left.\mathrm{ml}^{-1}\right)$ using a pipette. Each concentration of conidia was inoculated to $\geq 10$ leaves. After inoculation, the leaves were placed into petri dishes containing wet paper towel to retain the moisture and incubated at $25^{\circ} \mathrm{C}$ under a 12-h cycle of light and darkness. Leaves inoculated with the sterile distilled water were used as the negative control. To complete Koch's postulates, the fungus was reisolated from lesion margins according to the methods described above. The experiment was carried out three times and each treatment had three replicates.

Morphological analysis. Colony characteristics and pigment production on PDA were observed after 10 days at $28^{\circ} \mathrm{C}$. Colony growth rates were measured on the day 7 and day 10 . Conidia were collected from PDA after 10 days and mounted on glass slides in $85 \%$ lactic acid. Conidia size was measured according to methods described by Weir et al. (2012). Appressoria were induced to develop on the surface of hydrophobic glass plates in vitro. At least 30 measurements per structure were measured with a ZEISS Axio Imager A2m microscope using differential interference contrast illumination.

Molecular identification and phylogenetic analysis. Genomic DNA from the HYCG2-3 isolate was extracted using the method of Damm et al. (2008). The ITS, GAPDH, and partial sequences of the CHS-1 and ACT genes were amplified and sequenced using the primer pairs ITS-1F (Gardes and Bruns 1993) + ITS-4 (White et al. 1990), GDF1 + GDR1 (Guerber et al. 2003), CHS-354R + CHS-79F (Carbone and Kohn 1999), and ACT-512F + ACT-783R (Carbone and Kohn 1999), respectively. Polymerase chain reaction (PCR) was performed in an Eppendorf Nexus Thermal Cycler (Eppendorf) in a total volume of $25 \mu$ l. The ITS, GAPDH, CHS-1, and ACT PCR mixture contained $20 \mathrm{ng}$ of genomic DNA, $0.2 \mu \mathrm{M}$ each primer, and $12.5 \mu \mathrm{l}$ of $2 \times$ PCR Taq MasterMix (Applied Biological Materials Inc.). Conditions for PCR of these genes constituted an initial denaturation step of $3 \mathrm{~min}$ at $94^{\circ} \mathrm{C}$; followed by 30 cycles of $30 \mathrm{~s}$ at $94^{\circ} \mathrm{C}, 30 \mathrm{~s}$ at $55^{\circ} \mathrm{C}$, and $1 \mathrm{~min}$ at $72^{\circ} \mathrm{C}$; and a final denaturation step of $7 \mathrm{~min}$ at $72^{\circ} \mathrm{C}$. DNA sequences obtained (forward and reverse) were aligned and edited with the Molecular Evolutionary Genetic Analysis (MEGA6.06) using Clustal W (Thompson et al. 1994). All the sequences generated in this study were deposited in GenBank.

Phylogenetic analysis was performed with each gene as well as the concatenated sequence alignment of four housekeeping genes (ITS, GAPDH, CHS-1, and ACTIN) using MEGA 6.0 software (Tamura et al. 2013). The sequences of 35 Colletotrichum isolates were obtained from GenBank for the analyses. Furthermore, the sequences of $C$. boninense and $C$. hippeastri were used as outgroups. A multilocus phylogenetic tree was obtained using neighbor-joining analysis based on the Tamura three-parameter model with gaps complete delete option, and the tree was drawn with branch lengths measured in the number of substitutions per site. An interior-branch test using 1,000 bootstrap replications was performed to assess the relative stability of the branches.

\section{Results}

Symptom development. The disease development of anthracnose on the leaves of E. japonicus was observed in nature. In the early stage, there were some irregular chlorotic spots $(0.5$ to $1.8 \mathrm{~mm}$ in diameter, mean $0.98 \mathrm{~mm}$ ) that occurred on the adaxial surface of the leaves (Fig. 1B). These spots enlarged and coalesced to form large, regular to irregular chlorotic to necrotic spots (Fig. 1C). Finally, most of the spots formed dry lesions and extensive necrotic areas (Fig. 1D). Fungal fruiting bodies (acervuli) developed on these lesions in concentric rings (Fig. 1E and F), typical symptoms of this disease. Leaves inoculated with water only remained symptom free (Fig. 1A).

Pathogenicity of fungal isolates. By day 2, hyphae were observed in the center of wounds on leaves inoculated with $10^{7}$ conidia $\mathrm{ml}^{-1}$. Typical disease symptoms appeared on day 3 . By day 5 , lesions were 3 to $4 \mathrm{~cm}$ in diameter and coalesced, and several acervuli were observed. On day 6 , the necrotic areas had enlarged and contained numerous acervuli in concentric rings (Fig. 2). By day 8, surfaces of the inoculated leaves were wholly necrotic.

When the leaves were inoculated with $10^{6}$ and $10^{5}$ conidia $\mathrm{ml}^{-1}$, disease development was similar but was slower than when inoculated with

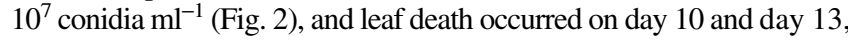
respectively. A fungus with the same morphological characteristics as HYCG2-3 was consistently reisolated from the necrotic leaves. Leaves inoculated with double-distilled $\mathrm{H}_{2} \mathrm{O}$ remained healthy.

Morphological characteristics of isolate HYCG2-3. After the HYCG2-3 was inoculated on PDA for 7 days, colonies of the agar produced strong brownish-orange pigmentation near the center (Fig. 3A). The average radial growth of the HYCG2-3 isolate on PDA was 8.2 $\mathrm{mm}$ day $^{-1}$. Aerial mycelia were dense, pale gray, and slightly felt-like (Fig. 3B). Conidia were hyaline, unicellular, smooth, and cylindrical. The ends of most conidia were obtuse but some were tapered toward the base ends, with some conidia tapering toward the basal end. Average conidial size was 15 to 20.2 by 5.1 to $6.7 \mu \mathrm{m}$, mean \pm standard deviation $=$ $17.4 \pm 1.0$ by $5.7 \pm 0.3 \mu \mathrm{m}$, and length/width ratio $=3.1$ (Fig. 3C).

Conidia germinated and developed appressoria on hydrophobic surfaces in vitro. Most conidia only developed an appressorium. Before germination, a medial septum developed, dividing the unicellular conidium into two cells of the same size (Fig. 4A). Germ tubes of different lengths grew from each cell of the conidium and produced pleurogenous, unicellular appressoria (Fig. 4A and B). A few conidia developed two appressoria. In this case, each cell of the two-celled conidium developed an appressorium (Fig. 4C and D). The appressoria developed either pleurogenously (Fig. 4C) or bipolarically (Fig. 4D). Most appressoria (92\%) were pear shaped (Fig. 4E and F), and the rest were irregularly shaped (Fig. 4G through $\mathrm{N}$ ). A few appressoria were two-celled (Fig. 4M and N). The average size of appressoria was 7 to 10.5 by 5 to $9.5 \mu \mathrm{m}$. Mature appressoria were darkly pigmented (Fig. 4). These morphological characteristics agree with the epitype of C. gloeosporioides sensu stricto (s.s.) (Cannon et al. 2008).
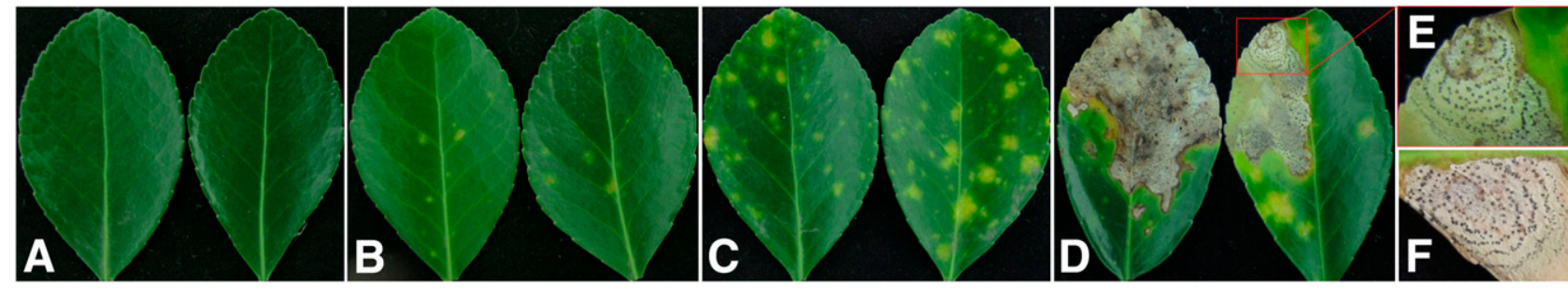

Fig. 1. Symptom development of anthracnose on the leaves of Euonymus japonicus. A, Healthy leaves. B, Chlorotic spots ( 0.5 to $1.8 \mathrm{~mm}$ in diameter, mean $0.98 \mathrm{~mm})$ on diseased leaves. C, Coalesced chlorotic spots on diseased leaves. D, Dry, necrotic lesions and extensive necrotic patches on diseased leaves. E, Enlarged lesion with the typical concentric circles of acervuli. F, Typical concentric circles of acervuli. 
The cuticle of HYCG2-3-infected leaves was removed and observed under the microscope after 7 days after inoculation. Compared with the hyphae that grew in dead leaf tissues, the apical cells of invading hyphae in the living cells seemed to be more coarse and less branched (Fig. 5A and B). Acervuli produced in infected tissues were subepidermal, typically with simple, short, erect conidiophores (Fig. 5C). Conidiogenous cells were hyaline and cylindrical, and most of them tapered toward the apex (Fig. 5D). Conidia in infected tissues were similar morphologically to those measured in vitro. Most appressoria were irregularly shaped, with dark-brown, thickened walls (Fig. 5E, i through xi).

Molecular characteristics of isolate HYCG2-3. The genes of ITS, CHS, GAPDH, and ACT from HYCG2-3 were sequenced and deposited in GenBank with the accession numbers KT033501 to KT033504. The ITS sequence of HYCG2-3 showed 100\% similarity with a $C$. gloeosporioides from the GenBank database (accession JQ580527.1). The GAPDH sequence showed 100\% similarity with C. gloeosporioides isolate CAUG15 (accession KP145401.1, GenBank). The CHS sequence showed $99 \%$ similarity with C. gloeosporioides isolate CAUG25 (accession KP1452382.1, GenBank). The ACT sequence showed $100 \%$ similarity with C. gloeosporioides strain C1014.6 (accession JX009462.1, GenBank).
The phylogenetic analysis of ITS sequences was performed with HYCG2-3, 35 ex-type strains, and authentic cultures of the Colletotrichum species complex, including C. nupharicola, C. fructicola, $C$. aeschynomenes, $C$. alienum, $C$. musae, $C$. siamense, $C$. asianum, C. queenslandicum, C. salsolae, C. gloeosporioides, C. alatae, C. xanthorrhoeae, C. horii, C. aotearoa, C. psidii, C. kahawae subsp. ciggaro, C. theobromicola, and G. cingulata "f. sp. camelliae" (Fig. 6). Among HYCG2-3, an ex-type strain of C. gloeosporioides s.s. (ICMP 17821) and six other authentic cultures of C. gloeosporioides s.s. strains formed a monophyletic lineage.

Phylogenetic analysis using the concatenated sequence alignment of four housekeeping genes $(1,452 \mathrm{bp})$, including ITS, CHS, GAPDH, and ACT, also showed that HYCG2-3 and ex-type and authentic strains of $C$. gloeosporioides s.s. were monophyletic, with significantly higher bootstrap support for these groups (Fig. 7). These results indicated that HYCG2-3 belongs to C. gloeosporioides s.s. in the $C$. gloeosporioides complex.

\section{Discussion}

Colletotrichum spp. cause anthracnose in a wide range of economically important plants. More than one species of Colletotrichum can affect a single plant species (Noireung et al. 2012). C. gloeosporioides
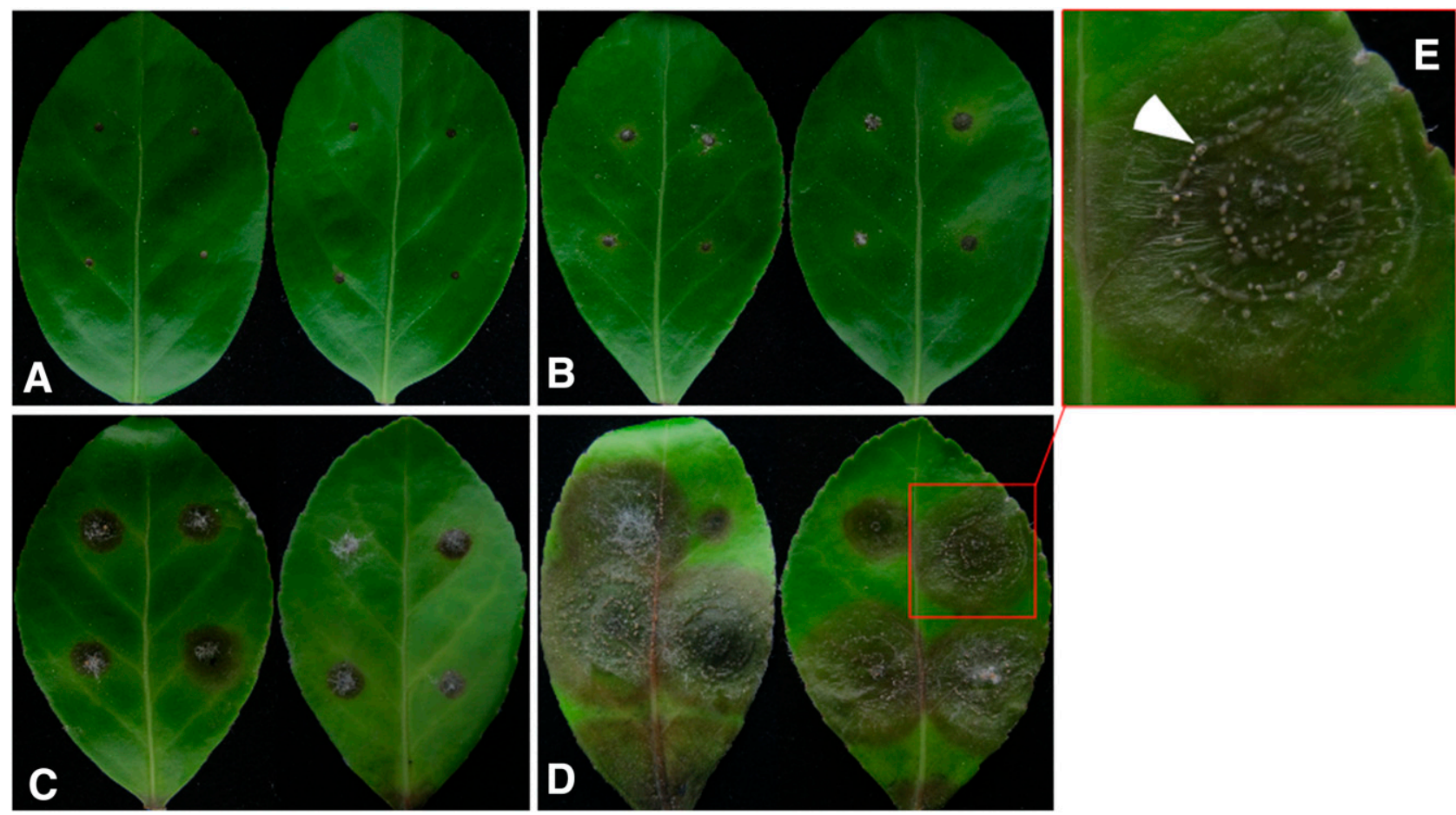

Fig. 2. Lesion development of HYCG2-3 on detached leaves of Euonymus japonicus after inoculation by conidia for 6 days. A, Negative control with double-distilled $\mathrm{H}_{2} \mathrm{O}$. B, Leaves

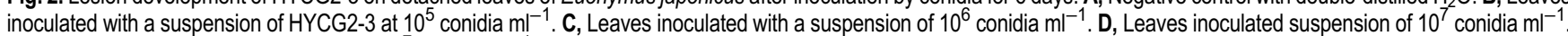
$\mathrm{E}$, Enlarged lesions on leaves inoculated $10^{7}$ conidia $\mathrm{ml}^{-1}$. Arrow indicates the concentric ring of fruiting bodies.
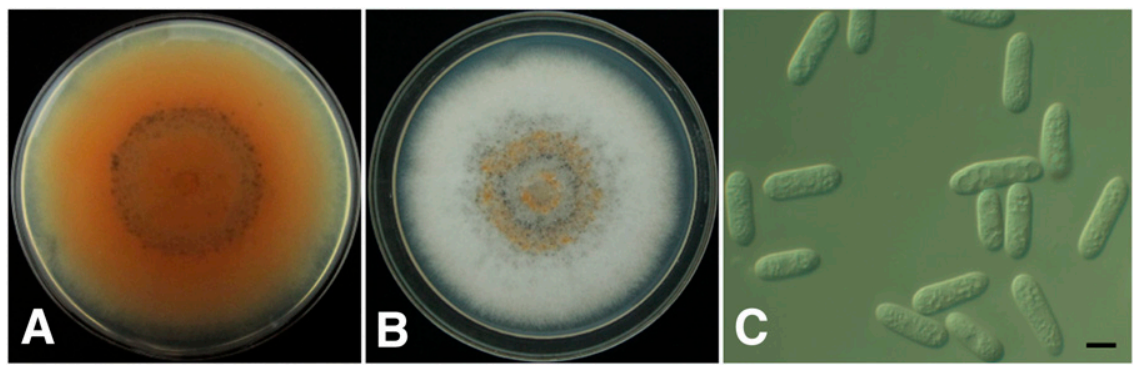

Fig. 3. Morphological characteristics of colonies and conidia of HYCG2-3. A, View of a colony showing pigmentation of the agar. B, View of a colony showing aerial hyphae and acervuli. C, Conidia. Scale bar $=5 \mu \mathrm{m}$. 
s.l. has been reported on E. japonicus in China, Japan, and the United States (Grand 1977; Kobayashi 2007; Parris 1959; Wu 1992). C. griseum Heald \& F. A. Wolf, C. boninense, and a Glomerella sp. were also reported to cause anthracnose on E. japonicus in the United States, Korea, and Japan, respectively (Anonymous 1960; Hemmi 1918; Kobayashi 2007; Lee et al. 2005). Wu (1992) reported several species of Colletotrichum from E. japonicus in China, including C. suttonii W. P. Wu (nom. inval., Arts 39.1, 40.1 [Melbourne] due to no Latin diagnosis; Index Fungorum 2015), C. crassipes (Speg.) Arx, C. griseum, C. gloeosporioides, and $C$. trichellum (Fr.) Duke. In the past, C. gloeosporioides s.s. was not sufficiently typified and epitypification is necessary for precise application of $C$. gloeosporioides s.s. Designating an epitype specimen with a separate living culture (ex-epitype) as well as the ITS sequence of ex-epitype was not done until 2008, when Cannon et al. (2008) epitypified this taxon to clarify the delineation of the species and subsequently stabilized the application of the name $C$. gloeosporioides s.s. Weir et al. (2012) studied the $C$. gloeosporioides complex, redelineated the species, and clarified the confusion using a multilocus approach. They accepted 22 species and one subspecies within $C$. gloeosporioides s.l. The true identities of the aforementioned members of $C$. gloeosporioides s.l. reported on E. japonicus remain unclear, however, and need to be further studied based on the latest developments by Cannon et al. (2008) and Weir et al.
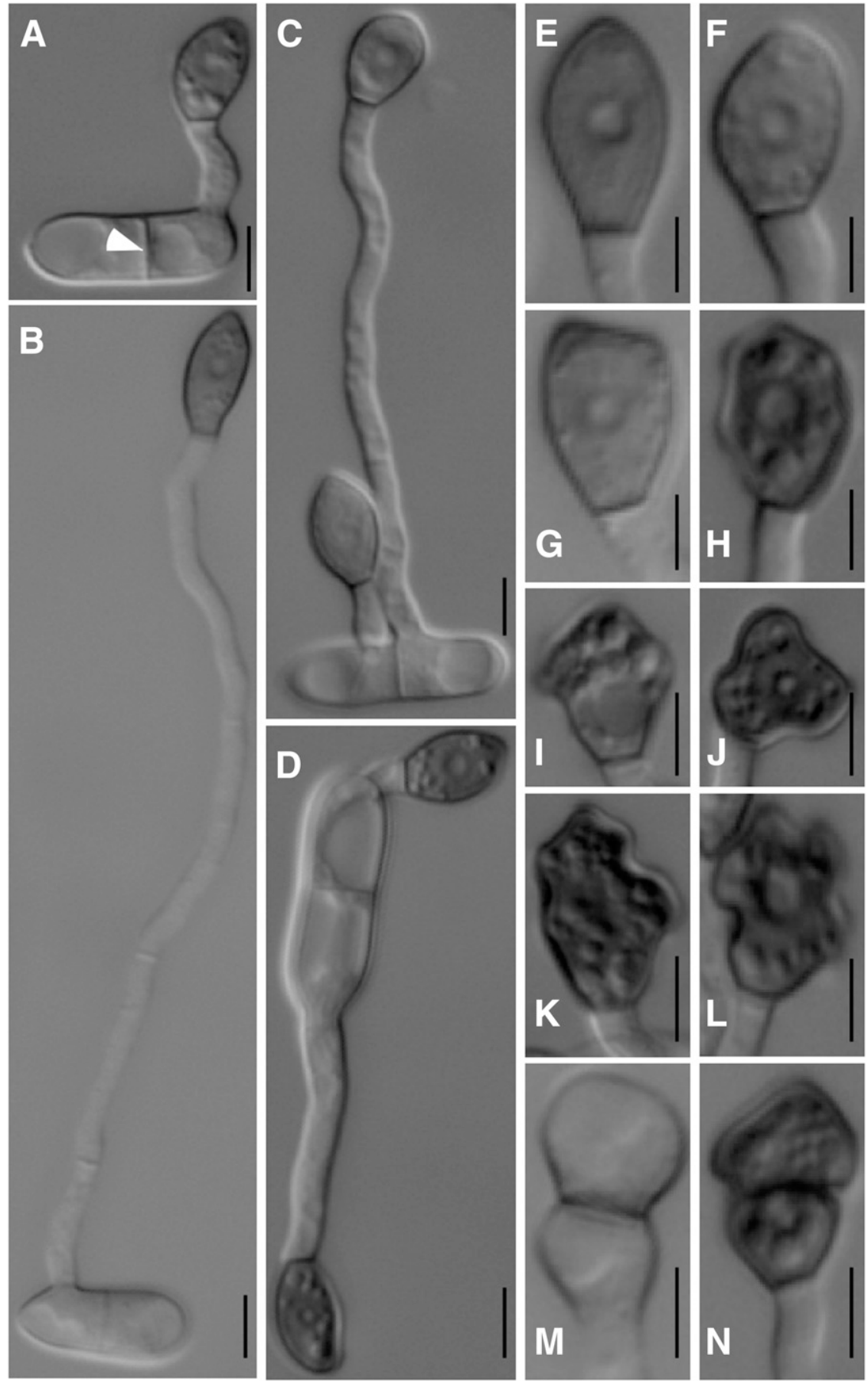

Fig. 4. Appressoria of HYCG2-3 germinated in vitro. A, Appressorium formed from a conidium with a short germ tube. Arrow indicates a septum of the conidium. B, Appressorium developed from a conidium with a long germ tube. C, Two pleurogenous appressoria formed on a conidium. D, Bipolar appressoria on a single conidium. $\mathbf{E}$ and $\mathbf{F}$, Pear-shaped appressoria. $\mathbf{G}$ through $\mathbf{N}$, Irregularly shaped appressoria. Scale bars $=5 \mu \mathrm{m}$. 
(2012). At present, it is unclear whether the C. gloeosporioides s.l. reported by Wu (1992) from the Shijiazhuang of Hebei Provinces of Northern China is conspecific with HYCG2-3 (C. gloeosporioides s.s.) collected from Nanjing of Jiangsu Provinces in Southern China. Further research is needed to determine the exact identity of Wu's species. Weir et al. (2012) indicated that the black spot pathogen on paper mulberry reported from China by Yan et al. (2011) is C. gloeosporioides s.s. Comparison of the 430-bp length of the ITS region of HYCG2-3 and C. gloeosporioides s.s. (accession number HQ 634378 in GenBank) reported by Yan et al. (2011) indicates a 98.6\% similarity.

The $C$. boninense species complex was studied by Damm et al. (2012) using multilocus molecular phylogenetic analysis (ITS, ACT, $\beta$-tubulin 2 (TUB2), CHS-1, GAPDH, histone (HIS3), and CAL) and segregated 18 species. Lee et al. (2005) sequenced 18S ribosomal DNA of $C$. boninense isolated from E. japonicus in South Korea and compared it with those in GenBank by BLASTing; however, they failed to provide an accession number for their sequence. Thus, the identity of this $C$. boninense in the species complex cannot be verified or determined.

In order to exactly distinguish the species of Colletotrichum from each other, morphological characteristics, including conidial size, shape, appressoria formation, sclerotia, setae, and acervuli, were used to describe some species of Colletotrichum. When Colletotrichum spp. infect host plants, infection occurs via an appressorium that develops from the germinating conidium on the plant surface, followed by turgor-driven penetration of the cuticle (Deising et al. 2000) and, in some cases, also of epidermal cells by infective hyphae (Bailey and Jeger 1992). Establishment within plant tissues is aided by host-induced virulence effectors delivered by appressoria and intracellular hyphae of the fungal pathogen (Kleemann et al. 2012; O'Connell et al. 2012). Therefore, appressoria are an important invading structure of $C$. gloeosporioides. In the present study, appressoria of $C$. gloeosporioides HYCG2-3 developed not only on hydrophobic glass surfaces but also in the living tissues of E. japonicus. However, the morphological characteristics of appressoria were variable. When appressoria formation was induced on hydrophobic surfaces in vitro, most appressoria were pear shaped and only a few were irregular. When leaves of E. japonicus were inoculated with HYCG2-3, the appressoria of $C$. gloeosporioides were mostly irregular in shape. These results suggested that the shape of appressoria is variable in different environments and not a stable taxonomic characteristic. For morphological identification, the shape of appressoria in vitro was more reliable.

The ITS sequence is a popular target for molecular characterization of eukaryotic microbes (Johannesson and Stenlid 1999; Malan et al. 2011). The ITS region in these microbes was used to develop a molecular marker for species identification. ITS has been adopted as a universal DNA barcode marker for fungi (Schoch et al. 2012) but, for some large fungal genera such as Colletotrichum and Alternaria, their species cannot be effectively differentiated solely using ITS sequence data (Brun et al. 2013; Weir et al. 2012). Thus, other genes are also used to differentiate among species, including ACT, HIS, CHS, and GAPDH (Cannon et al. 2012). In order to distinguish the different species of the $C$. gloeosporioides complex, the phylogenetic tree calculated from the alignment of concatenated sequences of ITS, GAPDH, CHS, and ACT was analyzed (Weir et al. 2012). In the current study, based on the analyses of the phylogenetic trees generated from the ITS sequences alone and concatenated sequences of ITS, ACT, CHS, and GAPDH, HYCG2-3 and ex-type and authentic cultures of $C$. gloeosporioides s.s. were clustered in the same clade with high bootstrap values (Fig. 7).

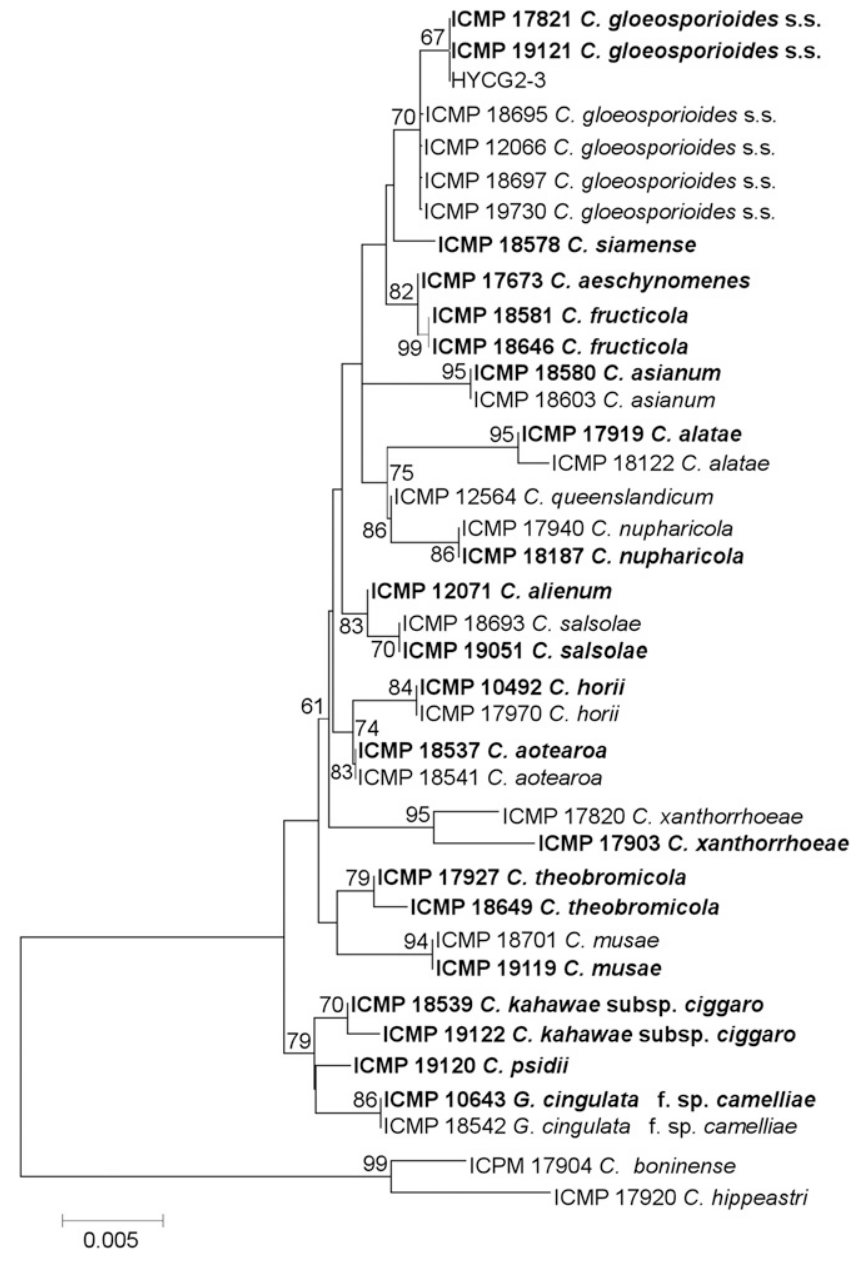

Fig. 6. Phylogenetic tree of HYCG2-3 with allied taxa calculated from internal transcribed spacer using neighbor-joining method. Bootstrap values $>60 \%(1,000$ replications) are given at the nodes. Ex-type and authentic cultures are emphasized in bold. Colletotrichum boninense and $\mathrm{C}$. hippeastri isolates are used as outgroups. $\mathrm{Bar}=0.005$ substitutions per nucleotide position

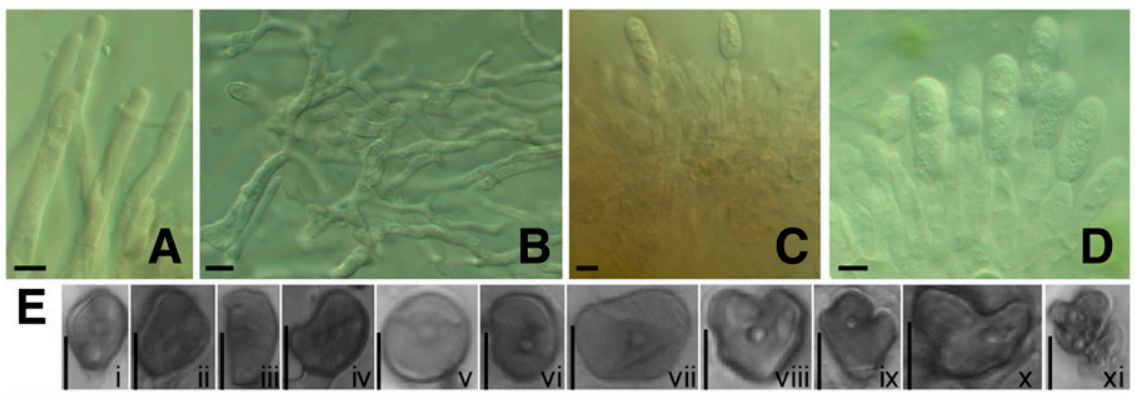

Fig. 5. Morphological characteristics of HYCG2-3 in infected leaves. A, Mycelium of HYCG2-3 in living leaf tissues. B, Mycelium of HYCG2-3 in dead tissues. C, Acervuli and conidiophores of HYCG2-3. D, Conidiogenous cells and conidium. E i through $\mathbf{x i}$, Variability of appressoria of HYCG2-3 in infected leaf tissue. Scale bars $=5 \mu \mathrm{m}$. 


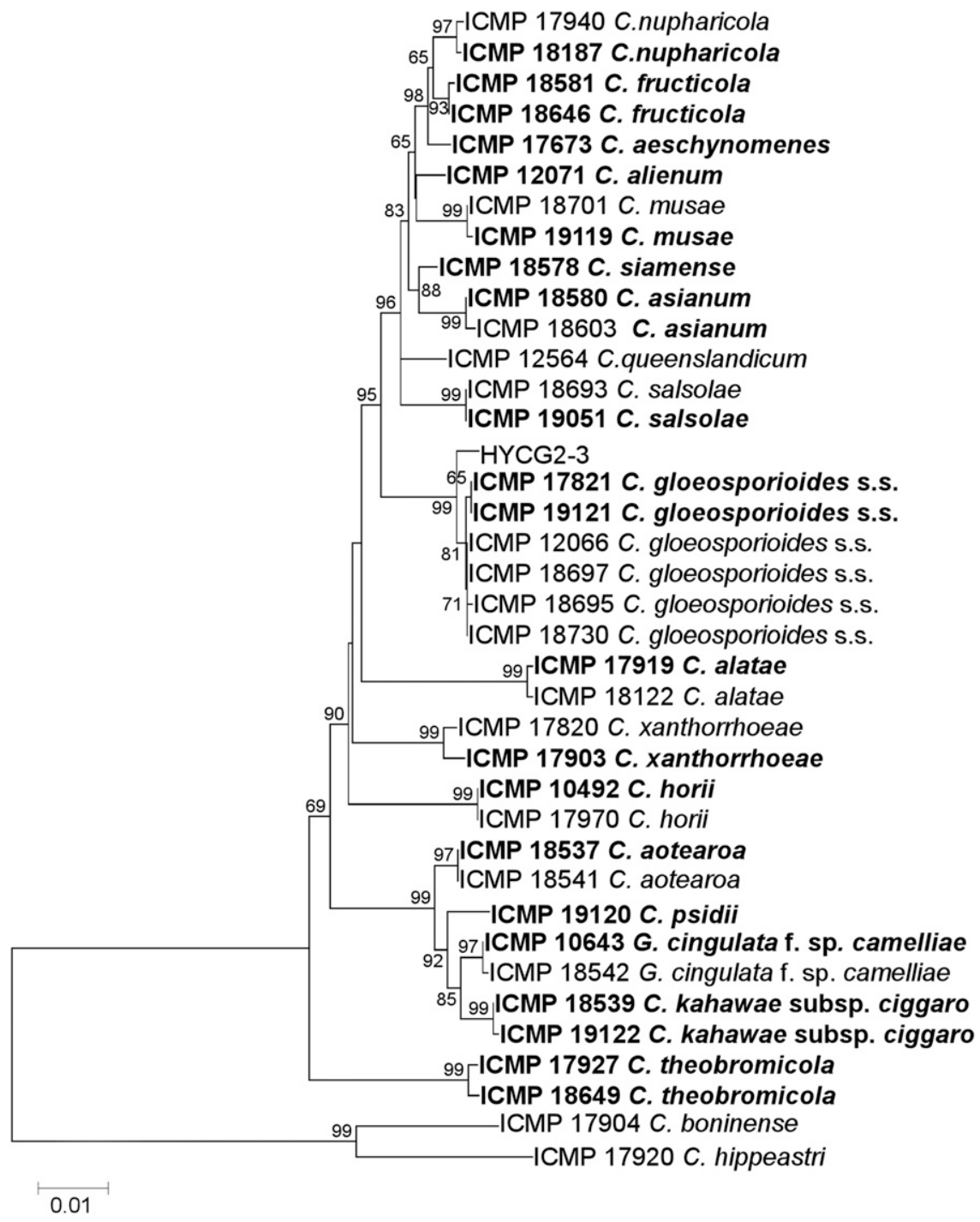

Fig. 7. Phylogenetic tree of HYCG2-3 with allied taxa calculated from concatenated sequences of ITS, GAPDH, CHS, and ACT using neighbor-joining method. bootstrap values $>60 \%$ (1,000 replications) are given at the nodes. Ex-type and authentic cultures are emphasized in bold front. Colletotrichum boninense and $C$. hippeastri isolates are used as outgroups. Bar $=0.01$ substitutions per nucleotide position.

In conclusion, $C$. gloeosporioides s.s. was identified as a pathogen causing anthracnose on E. japonicus in Nanjing, China in our study.

\section{Acknowledgments}

This work was financially supported by the Priority Academic Program Development of Jiangsu Higher Education Institutions (PAPD). We thank J. LaMondia for reviewing the manuscript.

\section{Literature Cited}

Anonymous. 1960. Index of Plant Diseases in the United States. Agricultural Handbook, Vol. 165. United States Department of Agriculture, Washington, DC.

Bailey, J. A., and Jeger, M. J. 1992. Colletotrichum. Biology, Pathology and Control. CAB International, Wallingford, UK

Brun, S., Madrid, H., Van Den Ende, B. G., Andersen, B., Marinach-Patrice, C., Mazier, D., and De Hoog, G. S. 2013. Multilocus phylogeny and MALDITOF analysis of the plant pathogenic species Alternaria dauci and relatives. Fungal Biol. 117:32-40.

Cannon, P. F., Buddie, A. G., and Bridge, P. D. 2008. The typification of Colletotrichum gloeosporioides. Mycotaxon 104:189-204.

Cannon, P. F., Damn, U., Johnston, P. R., and Weir, B. S. 2012. Colletotrichum-Current status and future directions. Stud. Mycol. 73: 181-213.

Carbone, I., and Kohn, L. M. 1999. A method for designing primer sets for speciation studies in filamentous ascomycetes. Mycologia 91: 553-556.
Crouch, J. A., Beirn, L. A., Cortese, L. M., Bonos, S. A., and Clarke, B. B. 2009 Anthracnose disease of switchgrass caused by the novel fungal species Colletotrichum navitas. Mycol. Res. 113:1411-1421.

Crous, P. W., Gams, W., Stalpers, J. A., Robert, V., and Stegehuis, G. 2004 MycoBank: An online initiative to launch mycology into the 21st century. Stud. Mycol. 50:19-22.

Damm, U., Cannon, P. F., Woudenberg, J. H. C., Johnston, P. R., Weir, B. S., Tan, Y. P., Shivas, R. G., and Crous, P. W. 2012. The Colletotrichum boninense species complex. Stud. Mycol. 73:1-36.

Damm, U., Mostert, L., Crous, P. W., and Fourie, P. H. 2008. Novel Phaeoacremonium species associated with necrotic wood of Prunus trees. Persoonia 20:87-102.

Dean, R., Van Kan, J. A., Pretorius, Z. A., Hammond-Kosack, K. E., Di Pietro, A. Spanu, P. D., Rudd, J. J., Dickman, M., Kahmann, R., Ellis, J., and Foster, G. D. 2012. The top 10 fungal pathogens in molecular plant pathology. Mol. Plant Pathol. 13:414-430.

Deising, H. B., Werner, S., and Wernitz, M. 2000. The role of fungal appressoria in plant infection. Microbes Infect. 2:1631-1641

Gardes, M., and Bruns, T. D. 1993. ITS primers with enhanced specificity for basidiomycetes-Application to the identification of mycorrhizae and rusts. Mol. Ecol. 2:113-118.

Grand, L. 1977. North Carolina Plant Disease Index. North Carolina Agricultural Experiment Station Technical Bulletin.

Guerber, J. C., Liu, B., Correll, J. C., and Johnston, P. R. 2003. Characterization of diversity in Colletotrichum acutatum sensu lato by sequence analysis of two gene introns, mtDNA and intron RFLPs, and mating compatibility. Mycologia 95:872-895

Hemmi, T. 1918. New anthracnose on Euonymus japonicus. Jpn. J. Phytopathol. 1 $9-15$ 
Huser, A., Takahara, H., Schmalenbach, W., and O'Connell, R. 2009. Discovery of pathogenicity genes in the crucifer anthracnose fungus Colletotrichum higginsianum, using random insertional mutagenesis. Mol. Plant-Microbe Interact. 22:143-156.

Index Fungorum. 2015. Index Fungorum. Online publication. http://www. indexfungorum.org

Johannesson, H., and Stenlid, J. 1999. Molecular identification of wood-inhabiting fungi in an unmanaged Picea abies forest in Sweden. For. Ecol. Manage. 115: 203-211.

Kamle, M., Kumar, P., Gupta, V. K., Tiwari, A. K., Misra, A. K., and Pandey, B. K. 2013. Identification and phylogenetic correlation among Colletotrichum gloeosporioides pathogen of anthracnose for mango. Biocatal. Agric. Biotechnol. 2:285-287.

Kirk, P. M., Cannon, P. F., Minter, D., and Stalpers, J. A. 2008. Dictionary of the Fungi, 10th ed. CAB International, Wallingford, UK.

Kirk, P. M., Stalpers, J. A., Braun, U., Crous, P. W., Hansen, K., Hawksworth, D. L., Hyde, K. D., Lücking, R., Lumbsch, T. H., and Rossman, A. Y. 2013. A withoutprejudice list of generic names of fungi for protection under the International Code of Nomenclature for algae, fungi, and plants. IMA Fungus 4:381-443.

Kleemann, J., Rincon-Rivera, L. J., Takahara, H., Neumann, U., Ver Loren van Themaat, E., Van Der Does, H. C., Hacquard, S., Stuber, K., Will, I., Schmalenbach, W., Schmelzer, E., and O'Connell, R. J. 2012. Sequential delivery of host-induced virulence effectors by appressoria and intracellular hyphae of the phytopathogen Colletotrichum higginsianum. PLoS Pathog. 8:e1002643

Kobayashi, T. 2007. Index of Fungi Inhabiting Woody Plants in Japan-Host, Distribution and Literature. The National Rural Education Association, Tokyo.

Lee, H. B., Park, J. Y., and Jung, H. S. 2005. First report of leaf anthracnose caused by Colletotrichum boninense on spindle trees. Plant Pathol. 54:254

Li, M., He, J., Ding, L., Kang, J., Zhang, Q., and Zheng, Q. 2007. Single spore strains without producing fruit body isolated from Cordyceps militeris and their RAPD analysis. Southwest China. J. Agric. Sci. 20:547-550.

Malan, A. P., Knoetze, R., and Moore, S. D. 2011. Isolation and identification of entomopathogenic nematodes from citrus orchards in South Africa and their biocontrol potential against false codling moth. J. Invertebr. Pathol. 108:115-125.

McNeill, J., Barrie, F., Buck, W., Demoulin, V., Greuter, W., Hawksworth, D., Herendeen, P., Knapp, S., Marhold, K., and Prado, J. 2012. International Code of Nomenclature for Algae, Fungi, and Plants (Melbourne Code). Koeltz Scientific Books, Koenigstein, Germany.

MycoBank. 2015. MycoBank. Online publication. http://www.mycobank.org

Narusaka, M., Shirasu, K., Noutoshi, Y., Kubo, Y., Shiraishi, T., Iwabuchi, M., and Narusaka, Y. 2009. RRS1 and RPS4 provide a dual resistance-gene system against fungal and bacterial pathogens. Plant J. 60:218-226.

Noireung, P., Phoulivong, S., Fang, L., Cai, L., Eric, H. C. M., Ekachai, C., Jones, E. B. G., Ali, H. B., and Hyde, D. K. 2012. Novel species of Colletotrichum revealed by morphology and molecular analysis. Cryptogam. Mycol. 33: 347-362.

Ocfemia, G. O., and Agati, J. A. 1925. The cause of anthracnose of avocado, mango and upo in the Philippine Islands. Philipp. Agricult. 14:199-216.

O'Connell, R., Herbert, C., Sreenivasaprasad, S., Khatib, M., Esquerré-Tugayé, M., and Dumas, B. 2004. A novel Arabidopsis-Colletotrichum pathosystem for the molecular dissection of plant-fungal interactions. Mol. Plant-Microbe Interact. 17:272-282.

O'Connell, R. J., Thon, M. R., Hacquard S., Amyotte, S. G., Kleemann, J., Torres, M. F., Damm, U., Buiate, E. A., Epstein, L., Alkan, N., Altmüller, J., AlvaradoBalderrama, L., Bauser, C. A., Becker, C., Birren, B. W., Chen, Z., Choi, J., Crouch, J. A., Duvick, J. P., Farman, M. A., Gan, P., Heiman, D., Henrissat, B., Howard, R. J., Kabbage, M., Koch, C., Kracher, B., Kubo, Y., Law,
A. D., Lebrun, M.-H., Lee, Y.-H., Miyara, I., Moore, N., Neumann, U. Nordström, K., Panaccione, D. G., Panstruga, R., Place, M., Proctor, R. H., Prusky, D., Rech, G., Reinhardt, R., Rollins, J. A., Rounsley, S., Schardl, C. L., Schwartz, D. C., Shenoy, N., Shirasu, K., Sikhakolli, U. R., Stüber, K., Sukno, S. A., Sweigard, J. A., Takano, Y., Takahara, H., Trail, F., van der Does, H. C., Voll, L. M., Will, I., Young, S., Zeng, Q., Zhang, J., Zhou, S., Dickman, M. B., Schulze-Lefert, P., Ver Loren van Themaat, E., Ma, L.-J., and Vaillancourt, L. J. 2012. Lifestyle transitions in plant pathogenic Colletotrichum fungi deciphered by genome and transcriptome analyses. Nat. Genet. 44:1061-1065

Parris, G. K. 1959. A revised host index of Mississippi plant diseases. Misc. Publ Vol. 1. Botany Department, University of Mississippi, Starkville, Mississippi.

Perfect, S. E., Hughes, H. B., O'Connell, R. J., and Green, J. R. 1999 Colletotrichum-a model genus for studies on pathology and fungal-plant interactions. Fungal Genet. Biol. 27:186-198.

Prusky, D. 1996. Pathogen quiescence in postharvest diseases. Annu. Rev. Phytopathol. 34:413-434.

Schoch, C. L., Seifert, K. A., Huhndorf, S., Robert, V., Spouge, J. L., Levesque, C. A., Chen, W., Bolchacova, E., Voigt, K., and Crous, P. W. 2012. Nuclear ribosomal internal transcribed spacer (ITS) region as a universal DNA barcode marker for Fungi. Proc. Natl. Acad. Sci. USA 109:6241-6246.

Shang, H., and Qiu, D. 1992. A preliminary study of etiology of anthracnose of Euonymus japonicus Thunb. J. Sichuan Agric. Univ. 10:189-199.

Shear, C. L., and Wood, A. K. 1907. Ascogenous forms of Gloeosporium and Colletotrichum. Bot. Gaz. 43:259-266.

Su, Y., Noireung, P., Liu, F., Hyde, K. D., Moslem, M. A., Bahkali, A. H., AbdElsalam, K. A., and Cai, L. 2011. Epitypification of Colletotrichum musae, the causative agent of banana anthracnose. Mycoscience 52:376-382.

Sutton, B. 1992. The genus Glomerella and its anamorph Colletotrichum. Pages 1-26 in: Colletotrichum: Biology, Pathology and Control. J. Bailey and M. Jeger, eds. CAB International, Wallingford, UK.

Sutton, B. C. 1980. The Coelomycetes: Fungi Imperfecti with Pycnidia, Acervuli and Stromata. Commonwealth Mycological Institute, Wallingford, UK.

Tamura, K., Stecher, G., Peterson, D., Filipski, A., and Kumar, S. 2013. MEGA6: Molecular evolutionary genetics analysis Version 6.0. Mol. Biol. Evol. 30: $2725-2729$

Thompson, J. D., Higgins, D. G., and Gibson, T. J. 1994. CLUSTAL W: Improving the sensitivity of progressive multiple sequence alignment through sequence weighting, position specific gap penalties and weight matrix choice. Nucleic Acids Res. 22:4673-4680.

von Arx, J. A. 1957. Die arten der gattung Colletotrichum Cda. Phytopathol. Z. 29: 413-468

Wang, J., Lai, S., and Xu, X. 1986. A preliminary study on the anthracnose of Euonymus japonicus. J. Zhejiang For. Coll. 3:73-77.

Weir, B. S., Johnston, P. R., and Damn, U. 2012. The Colletotrichum gloeosporioides species complex. Stud. Mycol. 73:115-180

White, T. J., Bruns, T., Lee, S., and Taylor, J. W. 1990. Amplification and direct sequencing of fungal ribosomal RNA genes for phylogenetics. Pages 315-322 in: PCR Protocols: A Guide to Methods and Applications. M. A. Innis, D. H Gelfand, J. J. Sninsky, and T. J. White, eds. Academic Press, New York.

Wu, W. 1992. Note on some Coelomycetes on Euonymus japonicus I. Melanoconiales. J. Hebei Acad. Sci. 1:65-74.

Yan, J., Wu, P., Du, H., and Zhang, Q. 2011. First report of black spot caused by Colletotrichum gloeosporioides on paper mulberry in China. Plant Dis. 95:880.

Yi, Y., Li, T., and Ouyang, J. 2003. Species of important pests in Euonymus japonicus in western Hunan and their prevailing regularity. For. Pest Dis. 4 14-16. 